Case Reports
in Dermatology

\title{
Type 1 Segmental Darier Disease: Case Report and Discussion of the Treatment Options
}

\author{
Sahar Hasan Alsharifa ${ }^{a}$ Dalal Alesa ${ }^{a} \quad$ Ahmed Baabdullah $^{b}$ \\ aDermatology Department, Alnoor Specialist Hospital, Makkah, Saudi Arabia; \\ ${ }^{b}$ Dermatology Teaching Assistant, King Abdul Aziz University, Jeddah, Saudi Arabia
}

\section{Keywords}

Darier disease $\cdot$ Segmental Darier disease $\cdot$ Type 1 segmental Darier disease

\begin{abstract}
Darier disease is a rare type of autosomal dominant genodermatosis, and it is caused by a mutation in the gene coding for the endoplasmic reticulum membrane calcium pump $\mathrm{Ca}^{2+}$ ATPase type 2, leading to compromised intercellular adhesion. Moreover, this condition is characterized by multiple keratotic greasy papules with a seborrheic distribution and is worsened by heat and sun exposure, sweating, and friction. Occasionally, it may be associated with nail abnormalities and may involve the mucosa. Unilateral segmental Darier disease is a rare variant characterized by unilateral eruption of erythematic keratotic papules not associated with other conditions. Herein, we report a case of type 1 segmental Darier disease. Furthermore, the main characteristics and treatment options are discussed.
\end{abstract}

\section{Introduction}

Darier disease, also referred to as Darier-White disease or follicular keratosis, was first described independently by Darier and White in 1889 [1]. It is a rare autosomal dominant disorder with a prevalence of about 1:30,000-1:100,000 [2]. The 10-year incidence of new 


\section{Case Reports in Dermatology}

Case Rep Dermatol 2020;12:159-167

DOI: 10.1159/000509177

(c) 2020

2020 The Author(s). Published by S. Karger AG, Basel

Alsharif et al.: Case of Darier Disease

cases is approximately 4 million [3]. Moreover, the condition equally affects male and female individuals. The symptoms of Darier disease usually appear during the first two decades of life, with a peak onset during puberty.

The clinical characteristics of the condition include multiple keratotic papules, which may coalesce in plaques, mainly in the seborrheic areas of the trunk, scalp (particularly its margins), forehead, and flexures.

About $10 \%$ of patients with Darier disease present with various localized lesions, such as unilateral, linear, segmental, and zosteriform [2]. Segmental Darier disease is classified into two phenotypes, namely, type 1 , which is caused by a postzygotic mutation in the $A T P 2 A 2$ gene during embryogenesis, leading to a mosaic pattern of skin involvement, and type 2 , which occurs in patients with generalized Darier disease with additional postzygotic mutation in the other alleles of ATP2A2 [2]. Herein, we report a rare case of clinically and histopathologically confirmed type 1 segmental Darier disease.

\section{Case Report}

A 35-year-old woman who presented with multiple pruritic skin lesions on the left breast for the past 5 years came to the outpatient dermatology department of our institution. Her symptoms were generally aggravated by exposure to high environmental temperatures. Thus, the lesions worsened during summer with a risk for regression during the other seasons. The number of lesions increased over time, and they extended to the left axilla. However, the patient had no family member presenting with similar lesions.

On local cutaneous examination, a group of normochromic and brownish keratotic papules, with linear disposition, was noted on the left breast, which extended up to the left axilla (Fig. 1a-c). However, no other abnormalities were observed. The examination of the scalp, nails, and mucous membranes did not show any abnormalities. The general physical and systemic examinations were not remarkable. All routine examination findings and laboratory parameters were within normal ranges.

A punch biopsy was performed on the lesion on the left breast, and the sample was subjected to histopathological examination, which revealed hyperkeratosis, acanthosis, striking suprabasal acantholysis, and dyskeratosis (basophilic cells with large nuclei and paranuclear halo as well as dyskeratotic cells, including grains and corps ronds) (Fig. 2a, b).

The patient was diagnosed with type 1 segmental Darier disease based on the clinical presentation and histopathological examination results. Moreover, she was instructed to prevent friction, and treatment with tretinoin cream $0.01 \%$ once per day before bedtime and hydrocortisone cream $1 \%$ once per day for 2 days per week resulted in a significant clinical clearance of the lesions within 1 month (Fig. 3a, b). The patient was followed up in the outpatient dermatology department for 2 years, and no recurrence was observed.

\section{Discussion}

Darier disease is an autosomal dominant disorder characterized by a symmetrical eruption of keratotic reddish-brown crusted papules and plaques with a seborrheic distribution mainly in the trunk. Moreover, some individuals experience mild involvement of the intertriginous areas. Characteristic nail changes, including white and red longitudinal bands, longitudinal nail ridges, and V-shaped nick at the free margin of the nail (which is a pathognomonic 


\section{Case Reports in Dermatology}

Case Rep Dermatol 2020;12:159-167

DOI: 10.1159/000509177

finding of Darier disease), can provide an important diagnostic information. Additional features of Darier disease include palmoplantar pits and whitish oral mucosal papules with a central depression (cobblestone appearance). In approximately $70 \%$ of patients, the initial lesions of Darier disease typically appear at ages between 6 and 20 years and peak during puberty [4]. However, in this case, the patient first developed the symptoms at the age of 30 years. Thus, the condition can be considered as a late-onset Darier disease.

The pathogenesis of Darier disease is correlated to mutations in the ATP2A2 gene located in chromosome 12, resulting in the dysfunction of the endoplasmic reticulum $\mathrm{Ca}^{2+}$ ATPase (SERCA2), which has an essential role in intracellular calcium signal transduction. These mutations lead to abnormalities in the calcium ATPase pump, consequently causing premature keratinization and acantholysis due to the loss of cell-to-cell adhesion [4].

Historically, Darier disease was first described by Darier and White in 1889. The localized form of Darier disease was first reported by Kreibich in 1906. However, it was believed to be caused by postzygotic somatic mutation in the ATP2A2 gene [5, 6]. This variant is often characterized by the absence of a family history and other features associated with typical Darier disease [7]. Similar to cases recorded in the literature, our patient with type 1 segmental Darier disease presented with skin lesions confined to a specific area, and her family members did not have similar symptoms.

The triggering factors of Darier disease include sun exposure, heat, sweating, friction, or infection [8]. Our patient had exacerbating factors similar to those presented in the literature. The use of lithium carbonate and calcium channel blockers is also a factor that can induce flares in Darier disease $[9,10]$. This condition is commonly accompanied by neuropsychiatric abnormalities, such as epilepsy, mood disorders, psychosis, and mental impairment [11]. Recently, in 2019, Cederlöf et al. [12] conducted a population-based cohort study to assess the association between Darier disease and type 1 diabetes mellitus, and this study found that patients with Darier disease had a nearly twofold increased risk of type 1 diabetes compared with the general population [12]. However, the segmental form of Darier disease is not usually associated with any systemic conditions as in our case.

All types of Darier disease have similar histopathological features. Segmental and generalized Darier diseases are histologically indistinguishable; both conditions are characterized by papillomatous epidermal hyperplasia with a combination of focal epidermal acantholysis and dyskeratosis. Acantholysis is more likely to be suprabasal, and two distinct types of dyskeratotic cells, namely, corps ronds and grains, are observed. Corps ronds are large, round acantholytic keratinocytes with dark nuclei surrounded by a bright pink rim of condensed keratin, and they are commonly located in the spinous layer. Meanwhile, grains are flattened cells comprising bright pink condensed keratin and a very thin dark nuclear remnant, and they are usually found in the stratum corneum [13]. The skin biopsy results of our patient were similar with those of previous studies.

In our case, Hailey-Hailey disease (familial benign pemphigus) is an important differential diagnosis. Darier disease and Hailey-Hailey disease are often discussed together as they are similar in terms of etiopathological characteristics. Both disorders are autosomal dominant inherited genodermatosis caused by abnormal epidermal calcium homeostasis. Darier disease is caused by mutations in the ATP2A2 gene found on chromosome 12q23-24.1. Meanwhile, Hailey-Hailey disease is caused by mutations in the ATP2C1 gene on chromosome 3q21-24. Moreover, there were similarities, including lesion sites (axilla and intertriginous areas), and worsening of symptoms caused by heat exposure, sweating, and secondary infections between Darier disease in our case and Hailey-Hailey disease. 


\section{Case Reports in Dermatology}

Case Rep Dermatol 2020;12:159-167

DOI: 10.1159/000509177 www.karger.com/cde

Alsharif et al.: Case of Darier Disease

By contrast, the age at presentation in our case is at 30 years. However, the age at onset is often earlier in Hailey-Hailey disease. Our patient was complaining of itching during the exacerbation period of the disease. However, itchiness may be less common in Hailey-Hailey disease.

Histopathological examination can differentiate Darier disease from Hailey-Hailey disease. Darier disease is characterized by acantholytic dyskeratotic cells (grains and corps ronds), which were observed in our case. However, Hailey-Hailey disease is characterized by incomplete acantholysis resulting in a dilapidated brick wall appearance.

There is no treatment guideline or specific therapy for type 1 segmental Darier disease. The main treatment goal is to control the symptoms and to improve quality of life. Based on the literature, behavioral measures, such as avoidance of triggering factors, improvement in hygiene, wearing of cotton clothes, regular use of emollients and sunblock (particularly during summer), and intermittent utilization of medium-potency topical corticosteroids, are generally sufficient to control the symptoms due to the low severity of the localized type of Darier disease [14]. In our case, to decrease the side effects correlated to the chronic use of topical corticosteroid (particularly in an occluded area, such as under the breast and axilla), the use of topical corticosteroids was limited to 2 days per week. For patients with diseases controlled by the treatment measures previously mentioned, the use of topical retinoids, such as tretinoin $0.05 \%$ cream, adapalene $0.1 \%$ cream, or tazarotene $0.05 \%$ cream, which is applied to the affected area once per day, is recommended if symptoms persist [15-17]. Several case reports have shown that tazarotene gel is more effective than other topical retinoids [17]. However, in this case, tretinoin $0.01 \%$ cream was used because it causes less irritation.

Other treatment options for the localized types of Darier disease include topical keratolytic agents, such as salicylic acid and lactic acid, which may improve the lesions by reducing hyperkeratosis. Moreover, antiseptic solutions (such as triclosan and astringents) and topical antibiotics (including fusidic acid and mupirocin) are effective in reducing secondary bacterial colonization and malodor [13]. Previous studies have shown that 5-fluorouracil, calcineurin inhibitors, and synthetic vitamin $\mathrm{D}_{3}$ analog are considered as treatment alternatives [18-22].

Systemic retinoids, such as isotretinoin and acitretin, are the most effective treatment modalities for the generalized types of Darier disease [23]. Other systemic therapies include cyclosporine and oral contraceptives [24-26]. Recent case reports on Darier disease showed that doxycycline was also effective [27]. This medication both chelates and assists calcium in crossing membranes, which may correct cellular calcium imbalance.

Surgical interventions can be an option for the persistent localized type of Darier disease, which is resistant to conventional treatment. These interventions include surgical excision, electrosurgery, dermabrasion, laser ablation, photodynamic or electron beam therapy, and injection of botulinum toxin particularly in a patient with excessive sweating [26, 28]. In 2015, Krakowski et al. [29] successfully treated a teenage boy with segmental Darier disease using ablative fractional laser resurfacing. However, although surgical interventions may be beneficial for several patients, recurrence can occur.

In our patient, favorable outcomes were observed with the use of both tretinoin cream $0.01 \%$ once per day before bedtime and hydrocortisone cream $1 \%$ once per day for 2 days per week. Thus, the application of low-potency topical corticosteroids for 2 days per week might help reduce the risk of irritation and relieve itching with low or no side effects. The treatment was well tolerated with excellent control of the disease. 


\section{Case Reports in Dermatology}

\section{Conclusion}

Segmental Darier disease is a rare inherited autosomal dominant disorder. Thus, a differential diagnosis of keratotic papular lesions with a linear distribution is important. Moreover, the diagnosis of segmental Darier disease, particularly when exacerbation caused by the triggering factors is observed, should not be ruled out due to the late age of presentation. Thus, a histopathological examination for any suspected lesions should be performed in order to confirm the final diagnosis. The treatment of type 1 segmental Darier disease in this study should be considered as it has excellent therapeutic outcomes but no adverse effects.

\section{Statement of Ethics}

The study was conducted in accordance with the Declaration of Helsinki. A written informed consent for the publication of this report, including images, was obtained from the patient.

\section{Conflict of Interest Statement}

The authors have no conflicts of interest to declare.

\section{Funding Sources}

This study did not receive any funding.

\section{Author Contributions}

S.A. performed the biopsy and diagnosed and treated the patient; hence, she is considered the first author. The patient still seeks consultation with S.A. in her dermatology clinic. Moreover, S.A. is primarily responsible for communication with the journal during manuscript submission, peer review, and publication process. S.A., D.A., and A.B. contributed to the study design and analysis and interpretation of data. Moreover, they revised the manuscript for relevant intellectual content and approved the final version. Finally, they are accountable in ensuring that questions related to the accuracy or integrity of any part of the work are appropriately investigated and resolved. All authors made a significant contribution to this study, and they have read and approved the final version of the manuscript.

\section{References}

1 Beck TA. De la Psorospermose folliculaire végétante, ou maladie de Darier. Annales de dermatologie et de syphilographie, Paris; 1904.

2 Medeiros PM, Alves NRM, Trujillo JM, da Silva CC, de Faria PCP, da Silva RS. Segmental Darier's disease: a presentation of difficult diagnosis. An Bras Dermatol. 2015;90(3 Suppl 1):62-5.

3 Savaş S, Koku Aksu AE, Sarıkaya E, Leblebici C, Gürel MS. Darier's disease: clinical and demographic features of nine cases. Turkderm Turkish Arch Dermatology Venereol. 2018;52(2):51-5. 


\section{Case Reports in Dermatology}

4 Dharman S, Arvind M. Darier's disease - oral, general and histopathological features in a 7 year old child. J Indian Soc Pedod Prev Dent. 2016 Apr-Jun;34(2):177-9.

5 Bordoloi AJ, Barua KN. Linear Darier's disease: a case with bilateral presentation. Indian Dermatol Online J. 2015 Sep-Oct;6(5):345-7.

6 Bakardzhiev I; Bakardzhiev Ilko. Darier Disease following Blaschko Lines - Case Report. J Clin Res Dermatology. 2016 Aug;3(6):1-2.

7 Palanisamy A, Kandasamy S, Vadivel S, Kothandapany S. Type one segmental Darier's disease. Indian J Dermatopathol Diagn Dermatol. 2015;2(2):34-6.

8 Burge SM, Wilkinson JD. Darier-White disease: a review of the clinical features in 163 patients. J Am Acad Dermatol. 1992 Jul;27(1):40-50.

9 Ehrt U, Brieger P. Comorbidity of keratosis follicularis (Darier's Disease) and bipolar affective disorder: an indication for valproate instead of lithium. Gen Hosp Psychiatry. 2000 Mar-Apr;22(2):128-9.

10 Nath AK, Udayashankar C. Diltiazem worsens Darier's disease. Int J Dermatol. 2014 Jan;53(1):e1.

11 Gordon-Smith K, Jones LA, Burge SM, Munro CS, Tavadia S, Craddock N. The neuropsychiatric phenotype in Darier disease. Br J Dermatol. 2010 Sep;163(3):515-22.

12 Cederlöf M, Curman P, Ahanian T, Leong IU, Brismar K, Bachar-Wikstrom E, et al. Darier disease is associated with type 1 diabetes: findings from a population-based cohort study. J Am Acad Dermatol. 2019 Dec;81(6):1425-6.

13 Suryawanshi H, Dhobley A, Sharma A, Kumar P. Darier disease: A rare genodermatosis. J Oral Maxillofac Pathol. 2017 May-Aug;21(2):321.

14 Cooper SM, Burge SM. Darier's disease: epidemiology, pathophysiology, and management. Am J Clin Dermatol. 2003;4(2):97-105.

15 Dogan S, Karaduman A, Erkin G, Gokoz 0. Effective treatment of linear Darier's disease with topical retinoids: case report and review of the literature. Acta Dermatovenerol Croat. 2011;19(3):206-9.

16 Casals M, Campoy A, Aspiolea F, Carrasco MA, Camps A. Successful treatment of linear Darier's disease with topical adapalene. J Eur Acad Dermatol Venereol. 2009 Feb;23(2):237-8.

17 Burkhart CG, Brukhart CN. Tazarotene gel for Darier's disease. J Am Acad Dermatol. 1998;38(6 I):1001-2.

18 Soenen A, Saint-Jean M, Daguzé J, Peuvrel L, Quéreux G, Dréno B. Combination of alitretinoin and topical 5fluorouracil in Darier disease. JAAD Case Rep. 2018 Dec;5(1):75-7.

19 Le Bidre E, Delage M, Celerier P, De Muret A, Lorette G. Traitement de la maladie de Darier par 5fluorouracile topique: quelle efficacité, quels risques? Ann Dermatol Venereol. 2010 Jun-Jul;137(6-7):455-9.

20 Rubegni P, Poggiali S, Sbano P, Risulo M, Fimiani M. A case of Darier's disease successfully treated with topical tacrolimus. J Eur Acad Dermatol Venereol. 2006 Jan;20(1):84-7.

21 Abe M, Yasuda M, Yokoyama Y, Ishikawa O. Successful treatment of combination therapy with tacalcitol lotion associated with sunscreen for localized Darier's disease. J Dermatol. 2010 Aug;37(8):718-21.

22 Kim WJ, Song M, Ko HC, Kim BS, Kim MB. Topical tacalcitol ointment can be a good therapeutic choice in erythromelanosis follicularis faciei et colli. J Am Acad Dermatol. 2012 Aug;67(2):320-1.

23 Christophersen J, Geiger JM, Danneskiold-Samsoe P, Kragballe K, Larsen FG, Laurberg G, et al. A double-blind comparison of acitretin and etretinate in the treatment of Darier's disease. Acta Derm Venereol. 1992;72(2):150-2.

24 Larbre B, Nicolas JF, Frappaz A, Thivolet J. [Cyclosporine and Darier's disease]. Ann Dermatol Venereol. 1993;120(4):310-1.

25 Shahidullah H, Humphreys F, Beveridge GW. Darier's disease: severe eczematization successfully treated with cyclosporin. Br J Dermatol. 1994 Nov;131(5):713-6.

26 Oostenbrink JH, Cohen EB, Steijlen PM, van de Kerkhof PC. Oral contraceptives in the treatment of DarierWhite disease - a case report and review of the literature. Clin Exp Dermatol. 1996 Nov;21(6):442-4.

27 Pettit C, Ulman CA, Spohn G, Kaffenberger J. A case of segmental Darier disease treated with doxycycline monotherapy. Dermatol Online J. 2018 Mar;24(3):13030/qt2827h6qq.

28 Ossorio-García L, Collantes-Rodríguez C, Villegas-Romero I, Linares-Barrios M. Vegetating darier disease treated with botulinum toxin. JAMA Dermatol. 2018 Jan 1;154(1):106-8.

29 Krakowski AC, Nguyen TA, Eichenfield LF. Treatment of segmental keratosis follicularis (darier disease) using ablative fractional laser resurfacing. Dermatol Surg. 2015 Apr;41(4):516-8. 
Case Reports in Dermatology
Case Rep Dermatol 2020;12:159-167

DOI: $10.1159 / 000509177$

(c) 2020 The Author(s). Published by S. Karger AG, Basel www.karger.com/cde
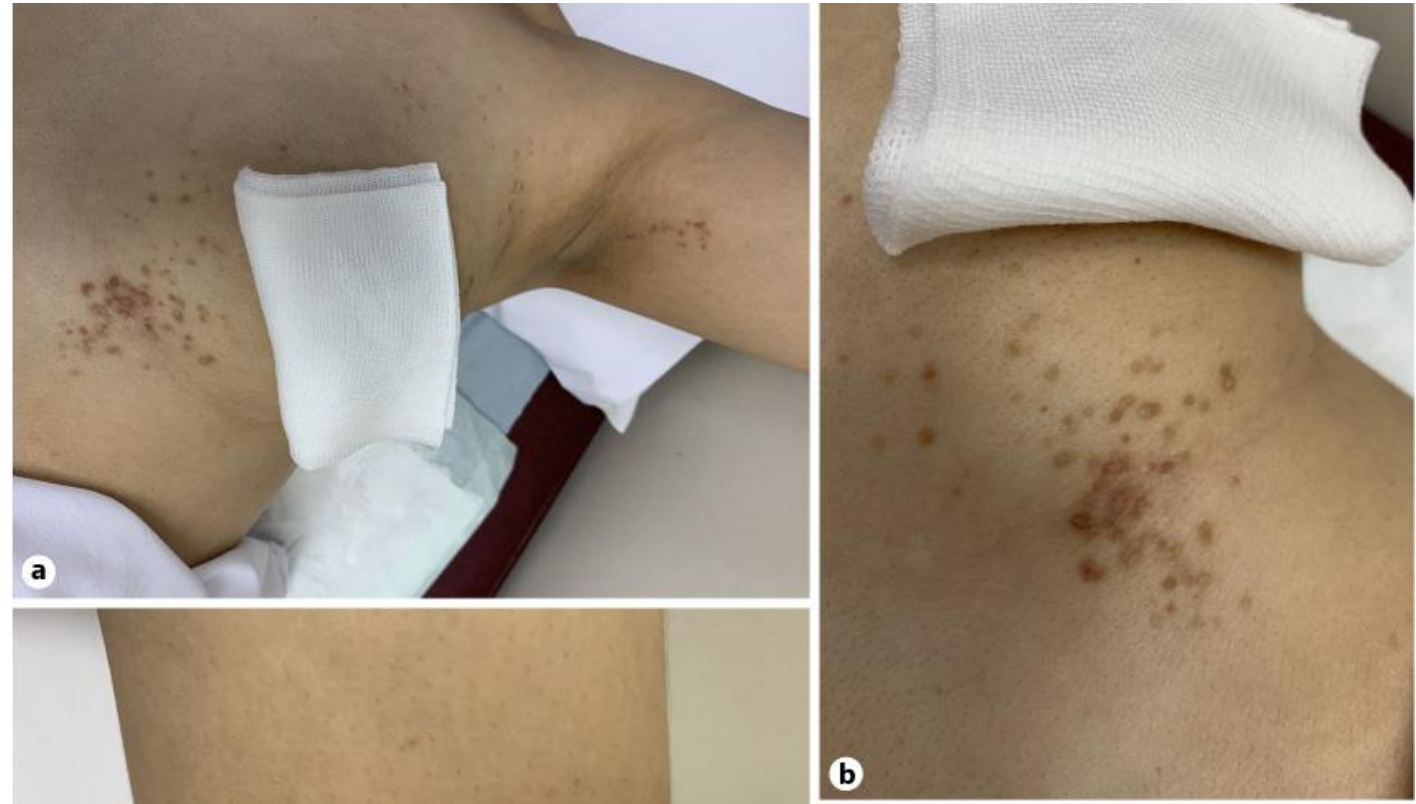

c

Fig. 1. a-c Clinical images before treatment. 


\section{Case Reports in Dermatology}
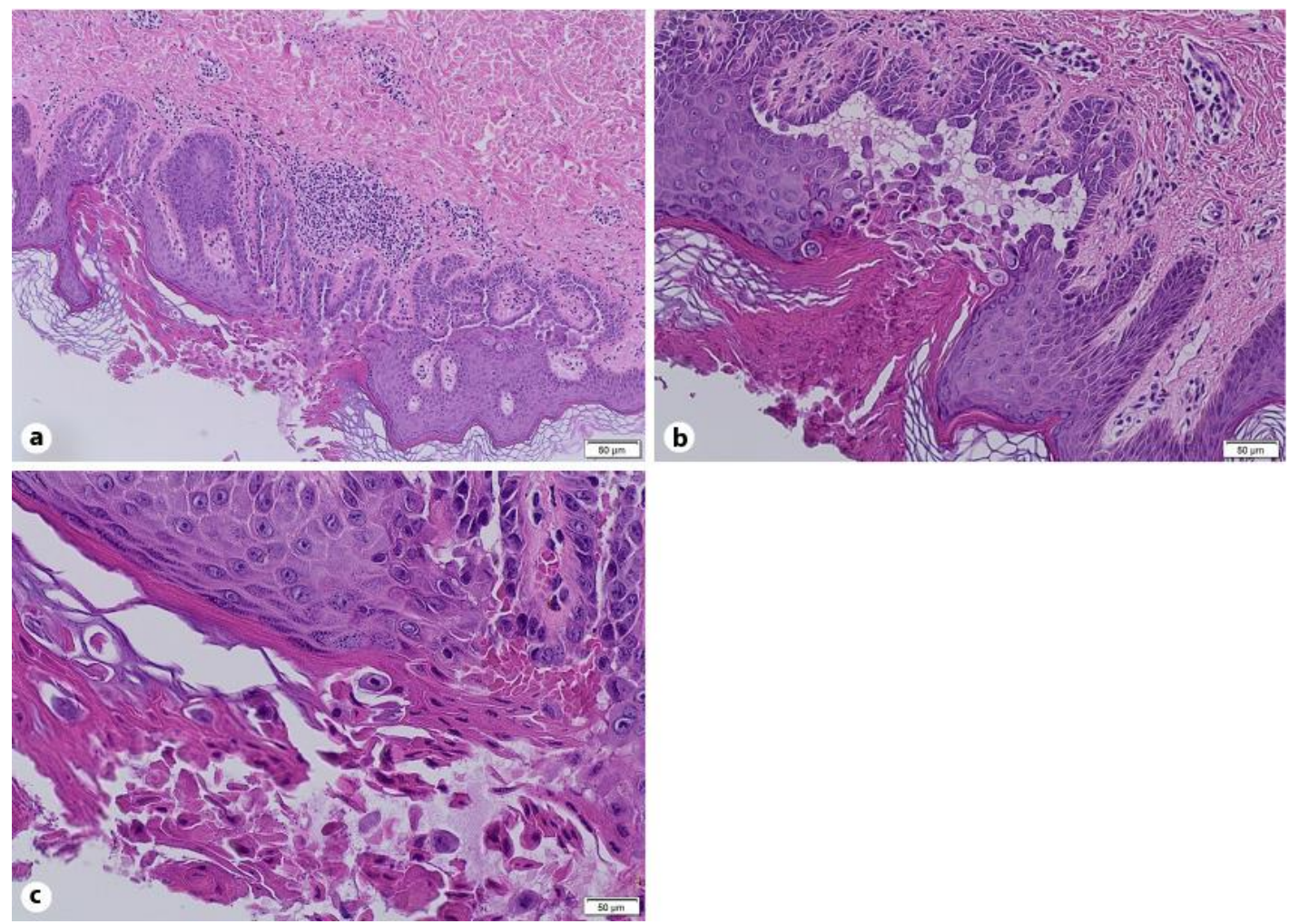

Fig. 2. a Epidermal and superficial dermal inflammatory process with suprabasal acantholytic clefting (hematoxylin and eosin staining, $\times 40$ ). b Suprabasal acantholytic clefting and foci of the thickened stratum corneum with parakeratosis (hematoxylin and eosin staining, $\times 100$ ). c Group of dyskeratotic cells: corps ronds and grains (hematoxylin and eosin staining, $\times 200$ ). 


\section{Case Reports in Dermatology}
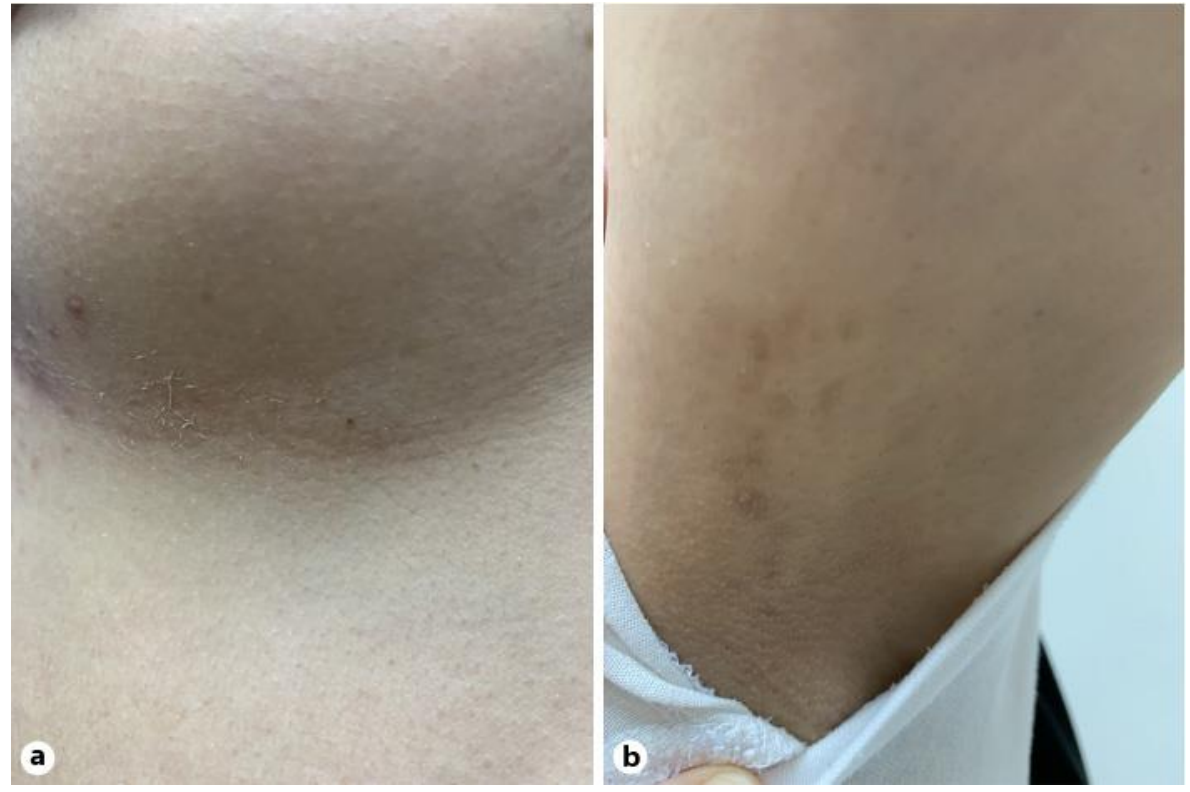

Fig. 3. a, b Clinical images after treatment. 